\title{
Grain for Green Project in farmers' minds: perceptions, aspirations and behaviours in eco-fragile region, Xinjiang, China
}

Pei Duan and Shengdong Chen

Shanxi University of Finance and Economics, Taiyuan, China

\author{
Heng Zhang \\ Chinese Academy of Social Sciences, \\ Institute of Finance and Banking, Beijing, China, and \\ Fuchun Zhang \\ Shanxi University of Finance and Economics, Taiyuan, China
}

Received 28 June 2020 Revised 11 October 2020

14 December 2020

8 January 2021

5 February 2021

Accepted 9 February 2021

\begin{abstract}
Purpose - This study aims to focus on the analysis of the internal mechanism of farmers' ecological cognition and the behaviour of Grain for Green Project (GGP), and the further relationship between ecological cognition and ecological aspiration, proposing climate change strategies and management from the perspective of farmers.

Design/methodology/approach - Theory of planned behaviour and social exchange theory were used to construct a theoretical framework and an ecological cognition under the influence of external factors, the aspiration and the behaviour of GGP, using ecological fragile areas in Bazhou and Changji, Xinjiang of 618 peasant households' survey data. The structural equation model and Heckman two-step model were applied to analyse the relationship between ecological cognition and ecological aspiration of farmers, the impact of peasant households' ecological cognition and aspiration to the behaviour of GGP and the influence factors of GGP behaviour.
\end{abstract}

Findings - This research's results show that the three characterizations of ecological cognitive variables, attitude towards the behaviour $(\mathrm{AB})$, subjective norms $(\mathrm{SN})$ and perceived behaviour control (PBC), have significant positive impact on farmers' GGP ecological aspiration. The comprehensive impact path coefficients of ecological cognition are $\mathrm{PBC}(0.498)>\mathrm{SN}(0.223)>\mathrm{AB}(0.177)$. Also, income change is a moderating variable, which has a significant moderating effect on the influence of $\mathrm{AB}$ and SN on ecological aspiration. Further, farmers' ecological cognition has an influence on the behaviour of GGP, and the change of farmers' income has a significant positive effect on farmers' choice of returning farmland to forests.

Practical implications - The ecological protection policy suggestions and countermeasures can be drawn from the research conclusions, adapted to China's ecologically fragile regions and even similar regions in the world to response the climate change.

(C) Duan Pei, Shengdong Chen, Heng Zhang and Fuchun Zhang. Published by Emerald Publishing Limited. This article is published under the Creative Commons Attribution (CC BY 4.0) licence. Anyone may reproduce, distribute, translate and create derivative works of this article (for both commercial and non-commercial purposes), subject to full attribution to the original publication and authors. The full terms of this licence may be seen at http://creativecommons.org/licences/by/4.0/ legalcode
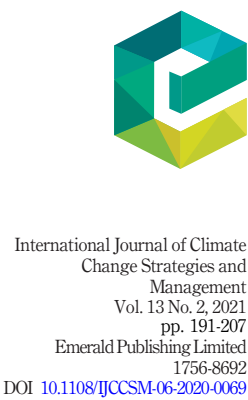
IJCCSM

13,2

192

Originality/value - Combining the theory of planning behaviour and social exchange, this paper empirically analyses the path of farmers' ecological cognition and ecological aspiration, as well as the influencing factors.

Keywords Grain for Green Project, Ecological cognition, Ecological aspiration, Ecological fragile region, Behaviour

Paper type Research paper

\section{Introduction}

Behind the rapid development of China's economy lie ecological problems such as resource constraints, environmental pollution and climate change. With the development of the reform and opening up over the past 40 years, there has been a crisis threatening regional sustainable development and public welfare. Therefore, the state has successively issued a series of ecological restoration projects, among which the Grain for Green Project (GGP) returning farmland to forest and grassland - is the earliest, largest, most invested and most widely involved ecological restoration project and ecological compensation project in the history of China's forestry (Li and Shi, 2015). The original intention of the GGP is ecological restoration. However, it is particularly difficult in ecologically fragile areas under the global climate change trend.

Since 1949, the main goal of forest resource management has been economic construction (Xian et al., 2020). However, following the devastating floods in 1998, the Party Central Committee and the State Council adopted "closing mountains, planting trees and returning farmland to forests" as an important measure for post-disaster reconstruction and remediation of rivers and lakes. Following to the introduction of the white book, "Returning Cropland to Forests in China for Twenty Years (1999-2019)", three provinces took the lead in carrying out the GGP pilot projects from 1999, and the GGP was launched nationwide in 2002. Great achievements have been made in the ecological environment of China, and the deterioration of the ecological environment has been gradually controlled since the implementation of the project.

With the smooth implementation of the three rounds of the project, the focus of the project has gradually changed from the participation of farmers to maintaining the achievements of the project. Since the 19th National Congress of the Communist Party of China, governments at all levels have attached great importance to the impact of the GGP on farmers' livelihoods. The 2020 "Opinions of the Central Committee of the Communist Party of China and the State Council on Doing a Good Job in the 'Three Rural' Areas to Ensure an All-round Well-off Society on Schedule" continue to promote the project of returning farmland to forests in poor ecologically fragile areas. GGP is an ecological compensation policy that respects the desire of farmers, and they can freely choose to enter and exit. On the one hand, farmers participating in GGP can obtain income from forestry products, and on the other hand, they can obtain ecological compensation from the government. Therefore, this is an inclusive policy to improve the welfare of forest farmers in China. The farmers who participate in the project are the basis and the main body of interest for the sustainable development of the project. As a result, the key to the sustainable development of the project is to balance the income and expenditure of the farmers who participate in the project; their sustainable livelihood is also the decisive factor for the success of the new round of the project.

Under the trend of global warming, the ecologically fragile rural areas in western China are the most sensitive to climate change. Therefore, GGP is not only limited to ecological restoration, but also assumes the responsibility of responding to climate change. Resources 
and the environment have been greatly damaged. The contradiction between farmers' livelihoods and ecological environmental protection is the most prominent (Pang, 2019). GGP is one of China's biggest programmes to deal with climate change. Xinjiang is an oasis agricultural area in northwest China. Its ecological environment is the most fragile in China. The GGP is a key project to build an ecological corridor and ecological security barrier and promote ecological restoration and ecological reconstruction, and it is also an effective way to adjust the agricultural industrial structure and tackle the key problem of targeted poverty alleviation. "The overall plan for the new round of GGP" is based on the principle of voluntary farmers and government guidance from the bottom up, and it does not limit the proportion of ecological forestry and economic forestry. In the five-year plan, ecological compensation is distributed three times: 800 yuan/mu in the first year, 300 yuan/mu in the third year, and 400 yuan/mu in the fifth year. At the same time, intercropping of forest and grain and the development of forest economy are allowed. This shows that the way of returning farmland is more flexible and the way of compensation is more convenient, and it has a good encouraging effect on farmers' participation behaviour.

The full text innovatively constructs a farmers' mind model of GGP, including ecological cognition, ecological aspiration and returning farmland behaviour, combined with the theory of planned behaviour, further constructs the internal influence path of ecological cognition and ecological aspiration. Innovatively using the survey data of farmers in the ecologically fragile area of Xinjiang, it has empirically analysed the impact of ecological cognition and ecological aspiration on the behaviour of GGP. That is to say, it analysed the cognition, aspiration and behaviour of farmers participating in major projects of climate change management and strategies.

\section{Literature review and conceptual framework}

\subsection{Literature review}

In recent years, there have been studies on the key points of farmers' returning farmland to forests, which can be summarized in the following three points: firstly, the research on farmers' willingness to participate in GGP includes not only the active willingness of farmers to participate in returning farmland to forests but also the negative willingness of farmers to return farmland (Sun and Feng, 2008; Chen et al., 2016; Zhang, 2019). Secondly, the research on the behaviour of farmers in the GGP is generally based on objective reality, which is more practical than focusing only on their willingness. Existing studies show that the behaviour of farmers in the GGP is affected by the family resource endowment and policy factors, including education level, per capita net income of families, income diversity, social capital and ecological compensation policies (Karanth and Nepal, 2012; Shi et al., 2019; Wang et al., 2017; Treacy, 2018). Thirdly, the impact of farmers' ecological cognition on their behaviour in relation to GGP may reveal inconsistencies between ecological cognition and ecological protection behaviour (Kotchen and Reiling, 2000; Liu et al., 2013; Song, 2010); in addition, farmers' risk perceptions will promote the behaviour of complex agroforestry management (Caveness and Kurtz, 1993; Wang et al., 2018). To sum up, most scholars have combined the theory of planning behaviour to analyse the ecological cognition, willingness and behaviour of farmers in relation to GGP, and analysed the influencing factors of the behaviour. However, the internal relationship between the ecological cognition and the behaviour of GGP is rarely studied, and the internal role of the ecological aspiration may not be considered.

Regarding the research on the effect of GGP in the arid and semi-arid ecologically fragile areas of western China, scholars have conducted in-depth research on the ecologically fragile areas in Northwest China, mainly analysing the reduction of ecological risks and threats to 
IJCCSM

13,2

194

food security since the implementation of the GGP policy and the impact on farmers' livelihoods, including non-agricultural employment, family income and farmers' conscious participation in ecological protection behaviours, in addition to farmers' risk perception of the policy of GGP (König, 2012; Liu and Lan, 2017; Zhang, 2018; Edward et al., 2019; Li, 2020). In addition, from the perspective of ecological economics and green development, to balance the relationship between environmental protection and economic development, it can compare the net benefits between fruit and vegetable gardens and natural protection forests to plan the scheme of GGP (Xian, 2020). Since the implementation of the GGP, the types of land use transfer have changed significantly, grassland degradation and soil and water loss have weakened, landscape connectivity has increased, vegetation coverage has increased and the total ecosystem service value has increased significantly (Sarkar and Padaria, 2016; Fan and Xiao, 2019; Wang and Yao, 2019; Wang et al., 2020). Li (2020) found that the utilization rate of nitrogen and phosphorus in animal and plant systems decreased after the implementation of the GGP, but the utilization rate of nitrogen and phosphorus in animal husbandry system increased. The main sources of organic fertilizer were livestock manure and urine.

Existing studies have provided good reference for this article and have also assisted in the implementation of the policy of GGP. However, there are few studies on the response of farmers to the GGP in Xinjiang, and there is no comprehensive analysis of farmers' ecological awareness, positive ecological aspirations and actual behaviour in the GGP. Therefore, this paper focuses on analysis of the internal mechanism of farmers' ecological cognition and their behaviour in the GGP, in addition to the further relationship between ecological cognition and ecological aspiration.

\subsection{Conceptual framework}

The GGP is a social system project that takes the participation of farmers as the main body and is a wide ranging and complex process conducted over a huge scale. As the main body participating in returning farmland, farmers are inevitably affected by the pre-existing factors of their own cognition, aspiration and behaviour. From the perspective of rational small-scale farmers (Duan et al., 2017), farmers' cognition, aspiration and behaviour in relation to returning farmland to forest is a rational evaluation of the visible income and input of the project (Gebregziabher and Soltani, 2019), which conforms to the social psychological hypothesis of social exchange theory (Blau, 1964; Tan et al., 2020). Social exchange theory is widely used in the research of organizational behaviour. Among the norms of social exchange theory, rational evaluation of input and income is the most widely used norm (Shore, 2009; Min et al., 2018). The balance between positive perceptions of benefits from the GGP and negative perceptions because of the costs will determine whether people support the GGP. Figure 1 shows the conceptual framework.

Combined with the visible input-output evaluation of social exchange theory, the main factors affecting the evaluation of farmers can be summarized as the social and economic status of farmers' families, the supply of social services after the conversion of farmland, the characteristics of farmers' family endowment and the characteristics of farmers' natural endowment of farmland, as shown in Figure 1. According to the nature of collective action of farmers' behaviour in returning farmland to forest and under the condition of information asymmetry, farmers inevitably have the psychology of "hitchhiking", which leads to the failure of collective action. After the second phase of returning farmland to forest, the sustainable maintenance of forest land is the key to the success of the effect of returning farmland to forest. Therefore, based on the cognition of farmers' returning farmland to forest, the analysis of farmers' ecological aspirations is the sticking point. On the basis of 
early behaviour, the key antecedents of sustainable investment in the project are determined.

The theory of planned behaviour generally analyses the causes of behaviour from three aspects: attitude towards the behaviour $(\mathrm{AB})$, subjective norms $(\mathrm{SN})$ and perceived behaviour control (PBC) (Ajzen, 1991; Shi et al., 2019). Based on the theory of planned behaviour, combined with the actual operation cycle of the current project and under the premise of input-output evaluation, the impact of farmers' ecological cognition on the behaviour of returning farmland to forest is analysed from the above three aspects of $\mathrm{AB}$, $\mathrm{SN}$ and PBC. On the one hand, farmers' behaviour in returning farmland to forest is reflected in whether they participate in the project of returning farmland to forest, which is further reflected in the actual area of the project in the early stage. On the other hand, their behaviour is reflected in the changes of the structure of the family labour allocation during the implementation of the project, that is, the structural proportion of the labour input in the economic forest, the labour input from migrant workers and the labour input in the ecological forest protection, all of which directly affect the proportion and total structure of household forestry income, ecological income and wage income.

Aspiration is in the satisfaction evaluation of Simon (1955); under a complex external environment, the decision-making body only has limited information processing ability, that is, limited rationality (You, 2018). It is the life, achievements and ideals of the surrounding groups that contribute to the formation of an individual's aspiration. Therefore, the difference between an individual's aspiration and current behaviour will affect his future actions. The ecological aspiration formed in the process of farmers' returning farmland to forest is the psychological state of farmers' cognition and the behaviour of surrounding farmers, which will affect their later ecological protection behaviour.

\section{Design and variable}

\subsection{Study area}

Since 2015, Xinjiang has fully implemented a new round of GGP, combining ecological restoration with characteristic industries; returning farmland to forest and grass with targeted poverty alleviation and development; and fully playing the ecological, economic and social composite benefits of GGP. Xinjiang is bounded by the Tianshan Mountains in the North-South direction and can be divided into North Xinjiang and South Xinjiang. Because of the differences in precipitation, temperature and human environment, the agricultural and forestry production environments in North Xinjiang and South Xinjiang differ. Therefore, the returned farmland areas selected in this study include Changji Prefecture in the north of Tianshan Mountain and Bazhou in the south of Tianshan Mountain, as shown in Figure 2.

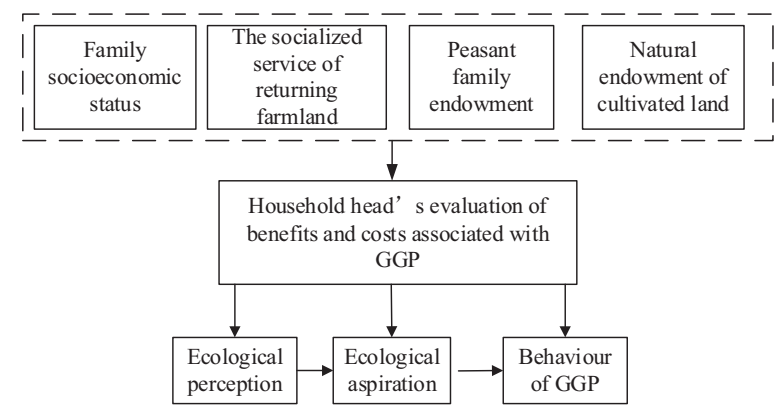

Figure 1. List of explanatory variables and main theoretical framework 
Figure 2.

Location of research area in exposed GGP region

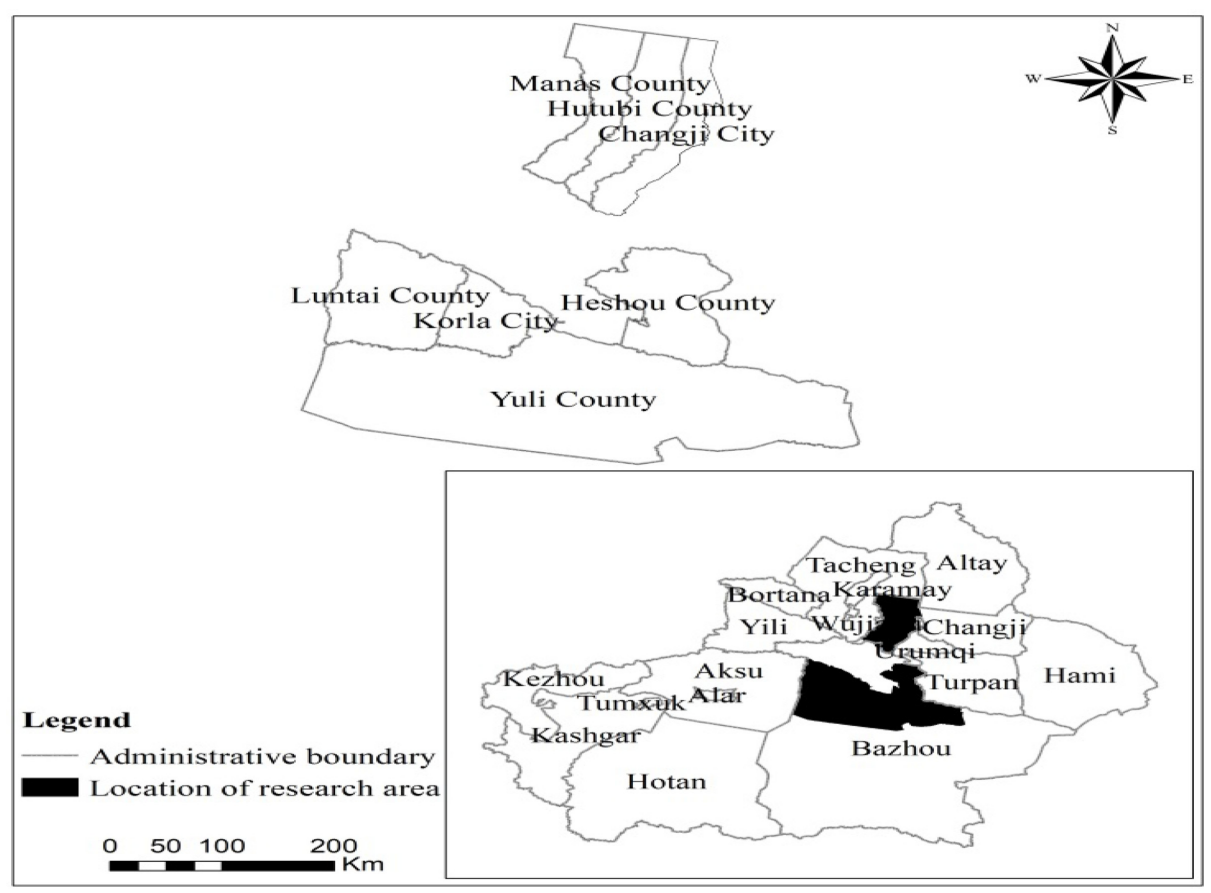

Changji Prefecture is adjacent to Urumqi, the capital of the autonomous region, and it has a good consumption market for the forest and fruit industry. The main implementation measures for returning farmland to forest and grass are to develop characteristic understory breeding, forest tourism, horticultural flowers, characteristic grape planting and brewing and desert grassland parks. Because of the nature of oasis agriculture, some areas are mostly desert, and the conversion of farmland to forests is mainly distributed in areas with more agricultural reclamation. Therefore, according to the concentration of agriculture, the most concentrated areas of agriculture and animal husbandry are selected as being representative.

\subsection{Data collection}

The data were collected through a household survey, for which a household questionnaire and structured interviews were the main tools. The questionnaire was modified following the information received through a pilot survey and field visits in November 2018. By using the method of stratified sampling and random sampling, four sample villages and towns were randomly selected from three sample counties in Changji and four sample counties and cities in Bazhou, respectively, and each county was randomly selected from four sample villages, and then 5-6 sample farmers were randomly selected from each village for one-toone questionnaire interview. A total of 650 questionnaires were sent out to identify and test the recovered questionnaire data. On the basis of validity analysis, 618 valid questionnaires were left for model analysis after removing the invalid samples. The sample efficiency was $95.08 \%$. 
3.3.1 Benefits and costs associated with Grain for Green Project. It has been found that farmers' input-output evaluation of the project is based on their socio-economic status, social services, family endowment and natural endowment of cultivated land. The actual investment involved includes the loss of cultivated land from agricultural production and the early investment of farmers in planting ecological forest or economic forest. The output includes the government's ecological compensation funds, the expected economic benefits brought by the economic forest, the expected benefits of the ecological forest and the positive ecological benefits. Farmers participate in the vertical comparison of the change of unit area income before and after the conversion of farmland to forest. The results of farmer comparison include that the income per unit area is greater than the expenditure, or less than or equal to the expenditure. If the income is greater than the expenditure, the value is 1 . And the income is less than or equal to the expenditure, the value is 0 . The analysis summarizes it as the change of income after the conversion of farmland, as shown in Table 1 below.

The evaluation of farmers' income from returning farmland to forests directly affects farmers' behaviour of GGP. The participation of farmland to forests is represented by dummy variables of 0 and 1 , and the participation is 1 and the non-participation is 0 . To further understand the actual area of farmers participating in the farmland conversion, the unit is mu; for all the farmers who understand the change of working time after the conversion, the less is represented by 0 , the unchanged is represented by 1 , the more is represented by 2 and the default working time for the farmers who do not participate in the conversion is unchanged.

3.3.2 Preset factors affecting the income and expenditure evaluation of farmers' Grain for Green Project. According to the above theoretical framework, preset factors include four aspects, including socioeconomic status of the family, socialized service of returning farmland, endowment of rural households and natural endowment of cultivated land. Among them, the measured variables, measurement methods and expected impact on dependent variables are shown in Table 1 above.

3.3.3 Farmers' ecological cognition and aspiration. Based on the theory of planned behaviour, the ecological cognition of farmers is analysed from three aspects: $\mathrm{AB}, \mathrm{SN}$ and $\mathrm{PBC}$. Aspiration is the boundary of farmers' preference, and farmers' ecological aspiration is the best choice that farmers think they can obtain, driving the behaviour of returning farmland to forest (Bernard and Taffesse, 2014). Aspiration is the reference point of farmers' decision-making on GGP. It is determined by the wealth of farmers and the economic results within the social scope and changes accordingly (Genicot and Ray, 2017). The target of desire will motivate farmers' actions to achieve the goal of ecological protection (Dalton, 2016). On the one hand, the ecological aspiration of farmers for GGP is the result of the balance between the ecological environment goal and the economic goal, and on the other hand, it also includes the perception of the ecological environment on their own health, as well as the perception of farmers' active control of the environmental behaviour to achieve the ecological aspiration. The specific measurement indicators are shown in Table 2 below, and the measurement method is Likert seven-level scale, where $1=$ strongly disagree, $2=$ disagree, 3 = disagree, $4=$ average, $5=$ somewhat agree, $6=$ relatively agree and $7=$ strongly agree.

\section{Econometric model}

\subsection{Structure equation modelling}

The structural equation model is selected to analyse the path relationship between the latent variables because SEM allows multiple categories of interpretation changes. The model can 


\section{IJCCSM \\ 13,2}

198

\begin{tabular}{l} 
Variables \\
\hline Behaviour of GGP \\
Whether or not \\
Returning area \\
Change of working time \\
after returning farmland
\end{tabular}

Definition

Yes $=1$, no $=0$

The actual number of mu to be converted to farmland

After participating in the farmland conversion, the time

of family work changed, $0=$ less, $1=$ unchanged and

$2=$ more

Benefits and costs associated with GGP

Earnings change (EC) Dummy variables with code 1 if the earnings of

household is positive, otherwise code 0

Family socioeconomic status

Income level (IL) The order of the income of the village where the farmer is located ( 1 means the lowest income, 7 means the highest income, increasing from 1 to 7 )

Wage level (WL) The GGP promotes the ability of labour to go out and earn wages ( 1 strongly disagree and 7 strongly agree)

$0.34 \quad 0.019$

$7.65 \quad 2.076$

$0.95 \quad 0.022$

Mean S.D. Exp

The socialized service of returning farmland
Socialized service $\quad$ The village provides socialized services, including

organization (SSO) individuals, enterprises, cooperatives and service centres, with $=1$ and without $=0$

$0.12 \quad 0.013+$

$3.6 \quad 0.053+$

$\begin{array}{lll}4.62 & 0.057+\end{array}$

$0.29 \quad 0.018-$

Peasant family endowment

The gender of the Dummy variables with code 1 for male-headed

household (GH) household, otherwise code 0

The age of the household Age of the household head in years

(AH)

Average education of the $1=$ no previous education (illiterate), $2=$ primary

household (AEH) school, $3=$ junior high school, $4=$ senior high school and $5=$ junior college or above

The number of labourers The number of household members in the age range of in household (NLH)

$16-60$ years and without labour loss

Natural endowment of cultivated land

Salinity of cultivated $\quad 1=$ no salinization, $2=$ small parts of cultivated land land (SCL) slightly salinized, 3 = part of cultivated land moderately salinized, $4=$ most cultivated land heavily salinized and $5=$ all cultivated land heavily salinized

Table 1.

List of explanatory variables and their definitions

\section{Fragmentation of} cultivated land (FCL) Cultivated land area/number of cultivated land blocks, unit: $\mathrm{mu} /$ piece

$\begin{array}{ccc}0.78 & 0.017 & + \\ 51.3 & 0.406 & - \\ 2.64 & 0.034 & + \\ & & \\ 2.33 & 0.04 & + \\ & & \\ 1.89 & 0.039 & +\end{array}$

Notes: + means that the expected influence of variables on the participation of GGP is positive and means that the expected influence is negative. S.D. means standard deviation and Exp means expectations

give the path results between the measurement variables and the structural variables simultaneously (Folmer and Oud, 2008). The SEM of this paper is as follows:

$$
\begin{gathered}
y=\Lambda_{y} \eta+\varepsilon \\
x=\Lambda_{x} \xi+\delta \\
\eta=B \eta+\Gamma \xi+\zeta
\end{gathered}
$$




\begin{tabular}{|c|c|c|c|c|}
\hline $\begin{array}{l}\text { Latent } \\
\text { variables }\end{array}$ & Indicators & Mean & S.D. & $\begin{array}{l}\text { Grain for } \\
\text { Green Project }\end{array}$ \\
\hline \multirow[t]{5}{*}{ As } & Ecological environment is as important as economic development & 4.61 & 0.044 & \\
\hline & The ecological environment has been very bad these years & 4.32 & 0.064 & \\
\hline & The deterioration of the ecological environment affects your health & 5.00 & 0.073 & \\
\hline & If there is no conversion programme, you will actively control the herd & 4.80 & 0.049 & \\
\hline & If there is no conversion programme, you will actively plant forest grass & 3.81 & 0.057 & \\
\hline \multirow[t]{3}{*}{$\mathrm{AB}$} & The GGP will help increase household income & 3.25 & 0.055 & \\
\hline & The GGP will help improve the ecological environment & 3.42 & 0.067 & \\
\hline & The GGP will help improve the living standards of families & 3.25 & 0.064 & \\
\hline \multirow[t]{2}{*}{$\mathrm{SN}$} & $\begin{array}{l}\text { You spend more time and energy on trees that have been converted than your } \\
\text { neighbours do }\end{array}$ & 3.29 & 0.062 & \\
\hline & $\begin{array}{l}\text { The government has made great efforts to publicize the knowledge and guidance } \\
\text { of farmland conversion }\end{array}$ & 3.48 & 0.073 & \\
\hline \multirow[t]{2}{*}{$\mathrm{PBC}$} & $\begin{array}{l}\text { The management technology of economic forest and ecological forest can be well } \\
\text { mastered }\end{array}$ & 4.83 & 0.06 & \\
\hline & The amount of government subsidy is reasonable & 4.44 & 0.062 & \\
\hline \multicolumn{4}{|c|}{ Notes: As means ecology aspiration; S.D. means standard deviation } & descriptive statistics \\
\hline
\end{tabular}

Equations (1) and (2) are measurement models, representing the relationship between observation variables and measurement variables, and equation (3) shows structural models, representing the relationship between potential independent variables ( $\mathrm{AB}, \mathrm{SN}$ and $\mathrm{PBC}$ ) and potential dependent variables (ecological aspiration). $\eta$ represents the endogenous latent variable, that is, farmers' ecological aspiration; $\xi$ represents exogenous latent variable, that is farmers' ecological cognition of GGP; $B$ and $\Gamma$ represent the coefficient matrix of endogenous and exogenous latent variables, respectively; and $\zeta$ represents the uninterpreted part. $y$ and $x$ represent the observation variable vectors of endogenous latent variables and exogenous latent variables, respectively; $\Lambda_{y}$ and $\Lambda_{x}$ represent the correlation coefficient matrix of observation variables and endogenous latent variables, observation variables and exogenous latent variables, respectively; and $\varepsilon$ and $\delta$ are residual terms.

\subsection{Two-step Heckman model}

The Heckman two-step model can be used to analyse the mantis-broken data with selection bias. The Heckman two-step model involves two equations, namely, the selection model and the result model. The selection model uses Logit return to analyse whether farmers participate in the project of returning farmland to forest. The result model calculates the inverse mills ratio (IMR) of the Logit regression results, and takes the result variables, ecological cognitive variables, aspiration variables and other control variables as independent variables. The ordinary least squares model is used to analyse the participating degree of impact.

\section{Empirical results analysis}

\subsection{Exploration of the functional relationship between ecological cognition and aspiration}

Before model analysis, we need to test the reliability and validity of the measurement variables [1]. Cronbach's alpha value was tested and analysed. All of which have passed the fitness test, and the test results have been greatly improved compared with the single-factor, two-factor and three-factor models, so the four-factor model has better aggregation validity and differentiation validity. 
IJCCSM

13,2

200

First of all, the test results of model fitness are analysed. Only the model that passes the test is analysable. The whole fitness test of the model was obtained by running AMOS 23.0: $\mathrm{chi}^{2} / \mathrm{df}=4.53$, less than 5 ; root mean square error of approximation $=0.076$, less than 0.1 acceptable standard (Steiger, 1990); and normed fit index $=0.933$, with an acceptable range greater than 0.9 (Bentler and Bonett, 1980). Comparative fit index $=0.946$ and $\mathrm{Hu}$ and Benlter (1999) gave a range greater than 0.9 as acceptable, while Tucker-Lewis index = 0.928 , greater than 0.9 . All fitness tests are in good agreement with the proposed confidence interval, which indicates that the model hypothesis path is reasonable.

Secondly, based on the premise hypothesis of social exchange theory, the ecological cognition and aspiration of farmers are based on the rational judgement of the income and expenditure of the project. Therefore, the judgement results of the income and expenditure of farmers participating in the project are classified variables, and the change of the income of farmers is regarded as the adjusting variable, and the income of farmers is compared in groups of the same and the increased. To analyse the relationship between farmers' ecological cognition and aspiration more deeply, the path coefficient differences of household structure model are analysed. The fitness test results of the model obtained by grouping are all in line with the recommended confidence interval, so the grouping results can be further analysed. The model path coefficients are shown in Table 3 below.

From the results in Table 3, it can be seen that the standardized path coefficient of ecological aspiration in the full sample analysis is significantly positive. By comparing the path coefficient of $\mathrm{AB}$ to ecological aspiration between the income increasing group and the income invariant group, we can see that the income increasing group is higher than the income invariant group.

The standardized path coefficient of farmers' SN for the ecological aspiration of GGP is significantly positive. The standardized path coefficient of $\mathrm{SN}$ to $\mathrm{AB}$ is also significantly positive, which indicates that the SN of farmers have a significant intermediary effect on ecological aspiration through $\mathrm{AB}$. Therefore, the total path coefficient of SN to ecological aspiration is: $0.122+0.57 \times 0.177=0.223$. The results of income grouping of $\mathrm{SN}$ on $\mathrm{AB}$ are significant. In addition, in the factor load results obtained, the monitoring function of neighbours is greater than the guiding function of government propaganda. Therefore, compared with the institutional environment, the positive guidance of relatives and neighbours is more conducive to the conversion of farmers' SN of GGP into effective ecological aspirations [2].

The standardized path coefficient of farmers' $\mathrm{PBC}$ on ecological aspiration is significantly positive. The standardized path coefficient of $\mathrm{PBC}$ to $\mathrm{AB}$ is significantly positive, that is, $\mathrm{AB}$ plays an intermediary role in the influence of $\mathrm{PBC}$ and ecological aspiration, so the total path coefficient of $\mathrm{PBC}$ to ecological aspiration is: $0.463+0.198 \times$ $0.177=0.498$. According to the grouping samples, the grouping results of $\mathrm{PBC}$ on ecological

Table 3.

Estimation results of multi-groups path coefficients

\begin{tabular}{|c|c|c|c|c|c|c|}
\hline \multirow[b]{2}{*}{ The path } & \multicolumn{2}{|c|}{ Full sample $(N=618)$} & \multicolumn{2}{|c|}{ Income invariant group $(N=542)$} & \multicolumn{2}{|c|}{ Income increase group $(N=76)$} \\
\hline & Estimate & S.E. & Estimate & S.E. & Estimate & S.E. \\
\hline $\mathrm{AB} \rightarrow \mathrm{As}$ & $0.177 * * *$ & 0.023 & $0.167 * *$ & 0.022 & $0.213^{* *}$ & 0.022 \\
\hline $\mathrm{SN} \rightarrow \mathrm{AB}$ & $0.57 * * *$ & 0.037 & $0.556 * * *$ & 0.038 & $0.591 * * *$ & 0.038 \\
\hline $\mathrm{SN} \rightarrow \mathrm{As}$ & $0.122 *$ & 0.019 & 0.093 & 0.019 & 0.127 & 0.019 \\
\hline $\mathrm{PBC} \rightarrow \mathrm{AB}$ & $0.198 * * *$ & 0.052 & $0.194^{* * * *}$ & 0.054 & $0.174 * * *$ & 0.054 \\
\hline $\mathrm{PBC} \rightarrow \mathrm{As}$ & $0.463 * * *$ & 0.032 & $0.444 * * *$ & 0.032 & $0.508 * * *$ & 0.032 \\
\hline
\end{tabular}

Notes: $* p<0.05 ; * * p<0.01 ; * * * p<0.001$ 
aspiration are all significant. In the income group, the path coefficients of behaviour control on the total aspiration are as follows: $0.444+0.194 \times 0.167=0.476$ in the income constant group, and $0.508+0.174 \times 0.213=0.545$ in the income increasing group. It can be seen that in the path coefficients of $\mathrm{PBC}$ on the total aspiration, the income increasing group is significantly greater than the income constant group. In addition, the standardized load coefficient of technical mastery (0.778) is greater than the expected standardized load coefficient of government subsidies (0.742).

Grain for Green Project in farmers' minds

\subsection{Analysis of influencing factors of farmers' conversion of farmland to forest}

To further explore the impact of ecological cognition and ecological aspiration on the results of farmers' early participation in the GGP, a two-stage Heckman model is established, and the control effect of the antecedents is considered. The results are shown in Table 4:

- The influence of ecological cognition and aspiration on the behaviour of GGP. AB variable has a significant positive impact on farmers' working time. The possible reasons are that farmers' expectation of income increase, improvement of living standards and improvement of ecological environment, which promote farmers' expectation of the project. $\mathrm{PBC}$ variable has a significant positive impact on the working time of farmers, that is, the farmers with stronger behaviour control ability will spend more time on working after returning farmland to forest. The ecological aspiration has a positive impact on the change of farmland conversion area and working time, but it is not significant. It is possible that ecological aspiration has not played a significant role in the positive promotion of farmers' participation in farmland conversion to forest.

- The influence of income change on the behaviour of GGP. The variable of income change, as the identifying variable, represents the variable that affects the choice of farmers' returning farmland to forest, but has no partial effect on the area of returning farmland and the working time, which helps to reduce the high correlation between the IMR and the explanatory variable in the second step, and reduces the multicollinearity problem. It can be seen from Table 4 that income change has significant positive coefficient in all four models, indicating that income change has significant positive effect on farmers' choice of returning farmland to forest.

- The influence of family socioeconomic status on the behaviour of GGP. Income level variable has a significant positive impact on the area of conversion. Wage level variables have a significant positive impact on farmers' choice of GGP.

- The influence of the socialized service on GGP. The variables of socialized service organizations have a significant positive impact on farmers' choice of returning farmland to forests. That is to say, compared with no socialized service individuals or organizations, farmers with socialized service individuals or organizations in their villages are more likely to choose to participate in the behaviour of GGP.

- The influence of farmers' family endowment on the behaviour of GGP. In Heckman model 1 , the gender variable of the household head has a significant negative impact on the area of returned farmland, that is, the female head of household is more involved in the area of returned farmland than the male head. Compared with men, traditional women are in a disadvantaged position in rural areas, so male heads of households are in the majority. Women who can be the heads of households are more concerned about programme (Ray et al., 2017; Kaeser and Willcox, 2018), so they are more likely to recognize the benefits of GGP and then participate in the larger area of returning farmland. 
IJCCSM

13,2

202

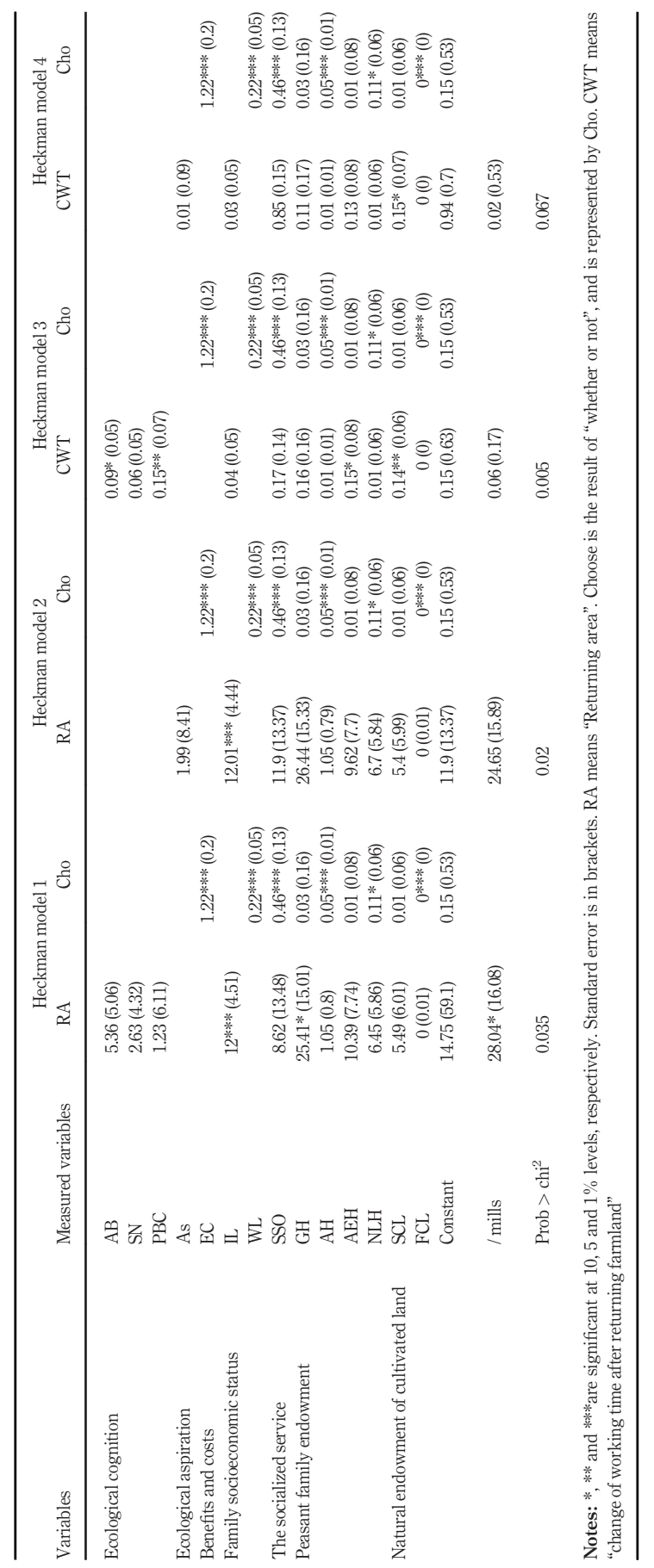

Table 4.

Analysis of influencing factors of farmers' participation in returning farmland to forest 
In the four models in Table 4, the age of the household head has a significant negative impact on the choice of GGP. In Heckman model 3, the education level of the household head has a significant negative impact on the change of working time. That is to say, the higher the education level of the head of household is, the farmers think that the change of working time after participating in the conversion of farmland becomes less. In the four models, the number of labours in the family has a significant positive impact on the choice of GGP. Farmers with more labour force have sufficient energy to manage more land, forestry and fruit industry, so the more likely they are to participate in the project:

- The influence of natural endowment of cultivated land on the behaviour of GGP. The salt alkalinity of cultivated land has a significant negative impact on the change of working time. That is to say, the higher the degree of salt alkalization of cultivated land in households, the less the change of working time after participating in the conversion.

\section{Conclusions and policy suggestions}

Based on the survey data of 618 farmers in Bazhou and Changji of Xinjiang, this paper studies the path of ecological cognition and ecological aspiration of farmers returning farmland to forest and analyses the difference in the relationship between ecological cognition and ecological aspiration. At the same time, the paper analyses the influence of ecological cognition and ecological aspiration on the behaviour of returning farmland to forest, in addition to the influence of external factors on the manner of implementation of the project. Important research conclusions are drawn to propose strategies and management from the perspective of farmers' participation in response to prominent climate change in ecologically fragile areas:

- The representational variables of farmers' ecological cognition of returning farmland to forests, attitudes towards the behaviour, SN and PBC all have significant positive effects on farmers' ecological aspirations. SN and PBC indirectly affect the ecological aspirations through the mediating role of $\mathrm{AB}$. The path coefficient of the standardized comprehensive influence of three dimensions of ecological cognition on ecological aspiration from large to small is $\mathrm{PBC}(0.498)>\mathrm{SN}$ $(0.223)>\mathrm{AB}(0.177)$. Comparing the difference of the impact of farmers' ecological cognition on ecological aspiration in the income invariant group and the income variable group, the change of income is a moderating variable that has a significant moderating effect on the impact of $\mathrm{AB}$ and $\mathrm{PBC}$ on ecological aspiration. The path coefficient of behavioural attitude on ecological aspiration is higher in the income increasing group than in the income invariant group.

- The ecological cognition of farmers has an impact on the behaviour of the GGP, and the more active the farmers are, the more time they devote to work after they participate in the conversion. Farmers with stronger behaviour control ability will spend more time on working after returning farmland to forest. After the implementation of the programme, farmers who believe that the programme can help increase their income are more likely to participate in it. Sufficient socialized service supply can promote the cognition, aspiration and behaviour of farmers to participate in the project.

According to the conclusions of the study, some policy suggestions are put forward for China's ecological fragile areas and even the ecologically vulnerable areas worldwide to 
IJCCSM

13,2

204

response the climate change. Mobilize farmers in fragile areas with high ecological value to measure the impact and destruction of their own development on the national and global ecosystems, and let them actively participate in the GGP. Firstly, the participation of farmers in the GGP is expected because of the ecological and economic objectives. Ecological cognition is based on the joint action of economic and ecological rationality. Therefore, policymakers should pay more attention to cultivating farmers' ecological cognition and then standardize the farmers' practice of returning farmland to forests. Moreover, they should promote farmers' effective ecological aspirations.

Secondly, the aim of increasing income is still the most important starting point for farmers to participate in the GGP. The driving and supervising role between neighbours is an important factor in farmers' active response to the behaviour of returning farmland to forest. Improving the behaviour control of farmers is the source of promoting farmers to increase ecological aspiration. Therefore, in the process of cultivating farmers' ecological cognition and aspiration, policymakers should improve farmers' behaviour of GGP. Thirdly, in the new round of implementation of the project, more attention should be paid to cultivating farmers' ecological aspirations, and then promote the transformation into effective behaviour of GGP. Policymakers should provide good service for the implementation of the project by building a good social service platform and improve the economic rational expectation of farmers' ecological cognition to promote more choices of farmers to participate in the GGP.

Finally, it is worth mentioning that there are still some deficiencies in this study: firstly, the cross-sectional data of Xinjiang farmers are used in this study, which cannot reflect the changes of time series farmers' ecological cognition and aspiration of returning farmland to forest. So, in the later stage, we will further track the ecological cognition, aspiration and behaviour of farmers' returning farmland to forest project. Secondly, dummy variables are adopted for farmers' participation in GGP, and data of farmers' memory are adopted for the area of farmland converted to forests. There are many error possibilities. In the following analysis, the method of geographic information system may be better used to avoid data errors.

Foundation projects: This paper is supported by the National Natural Science Foundation of China (project numbers 71903116 and 71903151), Postdoctoral Science Fund of China (214875), Youth Fund of Shanxi University of Finance and Economics (QN2019006) and Shanxi Social Science Planning Project (2020YY086). The lead author also acknowledges the functionaries of Bazhou Agricultural Bureau and Changji Agricultural Development Office and relevant unit to provide help to get in touch with the towns and villages. The authors also thank the teachers and graduate students from Xinjiang University and Xinjiang Agricultural University, who hardly participate in data collection.

\section{Notes}

1. Because of space, no results are given in the text, and can be obtained from the author if needed.

2. Because of space, no results are given in the text, and can be obtained from the author if needed.

\section{References}

Ajzen, I. (1991), "The theory of planned behavior", Organizational Behavior and Human Decision Processes, Vol. 50 No. 2, pp. 179-211.

Bentler, P.M. and Bonett, D.G. (1980), "Significance tests and goodness-of-fit in the analysis of covariance structures", Psychological Bulletin, Vol. 88 No. 3, pp. 588-606. 
Bernard, T. and Taffesse, A.S. (2014), "Aspirations: an approach to measurement with validation using Ethiopian data”, Journal of A frican Economies, Vol. 23 No. 2, pp. 189-224.

Blau, P.M. (1964), Exchange and Power in Social Life, Wiley Press.

Caveness, F.A. and Kurtz, W.B. (1993), "Agroforestry adoption and risk perception by farmers in Senegal”, Agroforestry Systems, Vol. 21 No. 1, pp. 11-25.

Chen, R., Jiang, Z.D. and Xie, C. (2016), "Analysis on rehabilitation willingness and influencing factors of farmers in returning farmland to returning farmland: based on survey of 1757 farmers in 17 provinces", Rural Economy, Vol. 6, pp. 38-44.

Dalton, P.S., Ghosal, S. and Mani, A. (2016), "Poverty and aspirations failure", The Economic Journal, Vol. 126 No. 590 , pp. $67-80$.

Duan, P., Wang, L.L. and Luo, J.C. (2017), "Individual response and influencing factors of technology intensive outsourcing in planting industry: take 631 wheat growers in Henan and Shanxi as examples", China Rural Economy, Vol. 8, pp. 29-44.

Edward, M., Robert, K.G. and Daniel, R.P. (2019), "Estimates of willingness to accept compensation to manage pine stands for ecosystem services", Forest Policy and Economics, Vol. 102, pp. 75-85.

Fan, M. and Xiao, Y.T. (2019), "Impacts of the grain for green program on the spatial pattern of land uses and ecosystem services in mountainous settlements in southwest China", Global Ecology and Conservation, Vol. 21, pp. 1-23.

Folmer, H. and Oud, J.H.L. (2008), "How to get rid of W: a latent variables approach to modelling spatially lagged variables", Environment and Planning A: Economy and Space, Vol. 40 No. 10, pp. 2526-2538.

Gebregziabher, D. and Soltani, A. (2019), "Exclosures in people's minds: perceptions and attitudes in the Tigray region, Ethiopia”, Forest Policy and Economics, Vol. 101, pp. 1-14.

Genicot, G. and Ray, D. (2017), “Aspirations and inequality”, Econometrica, Vol. 85 No. 2, pp. 489-519.

Hu, L. and Benlter, P.M. (1999), "Cutoff criteria for fit indexes in covariance structure analysis: conventional criteria versus new alternatives", Structural Equation Modeling: A Multidisciplinary Journal, Vol. 6 No. 1, pp. 1-55.

Kaeser, A. and Willcox, A. (2018), "Identifying women's attitudes and barriers to participating in a proposed community-based conservation group in Western Belize”, Ambio, Vol. 47 No. 5, pp. 622-633.

Karanth, K. and Nepal, S.K. (2012), "Local residents perception of benefits and losses from protected areas in India and Nepal”, Environmental Management, Vol. 49 No. 2, pp. 372-386.

König, H.J., Zhen, L., Helming, K., et al. (2012), "Assessing the impact of the sloping land conversion programme on rural sustainability in Guyuan, Western China”, Land Degrad. Develop.

Kotchen, M.J. and Reiling, S.D. (2000), "Environmental attitudes, motivations, and contingent valuation of nonuse values: a case study involving endangered species", Ecological Economics, Vol. 32 No. 1, pp. 93-107.

Li, G.P. and Shi, H.Y. (2015), "Ecological compensation standard for returning farmland to forests, farmer behaviour choice and profit and loss", China's Population, Resources and Environment, Vol. 25 No. 5, pp. 152-161.

Li, Z.Y., Sun, X.T., Huang, Z.H., et al. (2020), "Changes in nutrient balance, environmental effects, and green development after returning farmland to forests: a case study in Ningxia, China", Science of the Total Environment, Vol. 735, pp. 1-11.

Liu, Z. and Lan, J. (2017), "The effect of the sloping land conversion programme on farm household productivity in rural China", The Journal of Development Studies, Vol. 3, pp. 1-19.

Liu, X.F., Yang, Z.H. and Wang, Y.P. (2013), "Ecological cognition and behaviour decision-making of livestock and poultry farmers: based on field research of farmers in six provinces of Shandong and Anhui", China's Population, Resources and Environment, Vol. 23 No. 10, pp. 169-176. 
IJCCSM 13,2

Min, S., Bai, J., Huang, J. and Waibel, H. (2018), "Willingness of smallholder rubber farmers to participate in ecosystem protection: effects of household wealth and environmental awareness", Forest Policy and Economics, Vol. 87, pp. 70-84.

Pang, M. (2019), "Theoretical and practical exploration on climate change adaptability of ecologically fragile communities in Western China", Rural Economy, Vol. 10, pp. 93-100.

Ray, B., Mukherjee, P. and Bhattacharya, R.N. (2017), "Attitudes and cooperation: does gender matter in community-based forest management?", Environment and Development Economics, Vol. 22 No. 5, pp. 594-623.

Sarkar, S. and Padaria, R.N. (2016), "Farmers' awareness and risk perception about climate change in coastal ecosystem of West Bengal”, Indian Research Journal of Extension Education, Vol. 10 No. 2, pp. 32-38.

Shi, H.T., Wang, Z.Y. and Yan, L. (2019), “The influence of ecological cognition on farmers' grain for green behaviour: based on TPB and multi-group SEM", Land Science in China, Vol. 33 No. 3, pp. $42-49$.

Shore, L.M., Coyle-Shapiro, A.M., Chen, X.P., et al. (2009), "Social exchange in work settings: content, process, and mixed models", Management and Organization Review, Vol. 5 No. 3, pp. $289-302$.

Simon, H.A. (1955), "A behavioural model of rational choice", The Quarterly Journal of Economics, Vol. 69 No. 1, pp. 99-118.

Song, Y.Q. (2010), “Investigation and analysis of farmers' environmental awareness in developed areas: taking 714 samples in Suzhou as an example", Chinese Rural Economy, Vol. 73 No. 1, pp. 53-62.

Steiger, J.H. (1990), "Structural model evaluation and modification: an interval estimation approach", Multivariate Behavioral Research, Vol. 25 No. 2, pp. 173-180.

Sun, F. and Feng, K.W. (2008), "An empirical analysis of the factors affecting farmers' willingness to return farmland in the farming-pastoral ecotone", Agricultural Technology Economy, Vol. 5, pp. $45-51$.

Tan, Y.F., Lu, Q., Apurbo, S., et al. (2020), "Farmer's adoption tendency towards drought shock, risktaking networks and modern irrigation technology: evidence from Zhangye, Gansu, PRC", International Journal of Climate Change Strategies and Management, Vol. 12 No. 4, pp. 431-448.

Treacy, P., Jagger, P., Song, C., Zhang, Q. and Bilsborrow, R.E. (2018), "Impacts of China's grain for green program on migration and household income”, Environmental Management, Vol. 62 No. 3.

Wang, Y.F. and Yao, S.B. (2019), "Effects of restoration practices on controlling soil and water losses in the Wei river catchment, China: an estimation based on longitudinal field observations", Forest Policy and Economics, Vol. 100, pp. 120-128.

Wang, W., Ren, Q. and Yu, J. (2018), "Impact of the ecological resettlement program on participating decision and poverty reduction in Southern Shaanxi, China", Forest Policy and Economics, Vol. 95, pp. 1-9.

Wang, Z., Yu, Q. and Guo, L. (2020), "Quantifying the impact of the grain-for-green program on ecosystem health in the typical agro-pastoral ecotone: a case study in the Xilin Gol league, Inner Mongolia”, International Journal of Environmental Research and Public Health, Vol. 17 No. 16, pp. 1-16.

Wang, H.C., Gao, B., Qi, X.H., et al. (2017), "An empirical analysis of the impact of grassland ecological protection subsidy and incentive mechanism on herdsmen's livestock reduction behavior: based on a survey of 260 herdsmen in Inner Mongolia”, Agricultural Economic Problems, Vol. 38 No. 12, pp. 73-80.

Xian, J., Xia, C. and Cao, S. (2020), “Cost-benefit analysis for China's grain for green program”, Ecological Engineering, Vol. 151, pp. 1-10.

You, L., Liu, J.D. and Huo, X.X. (2018), “Aspiration, investment and poverty: a theoretical framework”, China Rural Observation, Vol. 5, pp. 29-44. 
Zhang, C.H. (2018), "Factors affecting risk perception of farmers in the new round returning farmland to forest project in the Aksu region", Resources Science, Vol. 40 No. 7, pp. 1387-1396.

Zhang, C.H. (2019), “The generating logic of farmers' willingness to participate in returning farmland: economic rationality or ecological rationality", Issues of Forestry Economics, Vol. 39 No. 5, pp. 449-456.

Grain for
Green Project
in farmers
minds

207

\section{Corresponding author}

Fuchun Zhang can be contacted at: 411970497@qq.com

For instructions on how to order reprints of this article, please visit our website: www.emeraldgrouppublishing.com/licensing/reprints.htm Or contact us for further details: permissions@emeraldinsight.com 